\title{
Liberdade Assistida no Horizonte da Doutrina de Proteção Integral
}

\author{
Leila Maria Torraca de Brito ${ }^{1}$ \\ Universidade do Estado do Rio de Janeiro
}

\begin{abstract}
RESUMO - O trabalho tem como objetivo abordar o significado da medida socioeducativa de liberdade assistida no contexto da doutrina de proteção integral. Por meio de uma revisão crítica da literatura, recordam-se conceitos e práticas utilizados na vigência da antiga doutrina da situação irregular, sustentando-se a importância de ruptura com modelos de atendimento empregados naquela época. Expõe-se, por fim, referenciais e procedimentos indicados aos que atuam com crianças e adolescentes que aportam à justiça da infância e da juventude, com destaque para ações e parcerias que podem ser estabelecidas em programas socioeducativos.
\end{abstract}

Palavras-chave: liberdade assistida; adolescentes em conflito com a lei; psicologia jurídica.

\section{Assisted Freedom in the Horizon of the Integral Protection Doctrine}

\begin{abstract}
The present work intends to analyze the significance of the socioeducative measure of assisted freedom within the context of the integral protection doctrine. By means of a critical revision of the literature, it also brings up concepts and practices used during the old doctrine of irregular situation, emphasizing the importance of rupture with the models of attendance then used. Finally, the article points out references and procedures indicated to those who act with children and adolescents who come to the child and youth court, with emphasis on actions and partnerships that can be established in social educative programs.
\end{abstract}

Key words: assisted freedom; adolescents in conflict with the law; forensic psychology.

O Estatuto da Criança e do Adolescente - ECA (1990) dispõe um leque de medidas socioeducativas direcionadas aos adolescentes em conflito com a lei, entre elas a de liberdade assistida (LA) ${ }^{2}$. Incluída - junto com a prestação de serviços à comunidade, a reparação do dano e a advertência - no repertório de medidas a serem cumpridas em meio aberto, a liberdade assistida é vista por estudiosos (Porto, 1999; Soares, 2001) como uma proposta que pode colaborar, em muito, para o desenvolvimento do potencial do assistido.

No presente trabalho objetiva-se discutir o significado dessa medida, assim como explorar algumas possibilidades de sua execução por programa de atendimento, que deve ter como parâmetro a doutrina da proteção integral, base da legislação vigente no país na referência a crianças e a adolescentes.

A preocupação com questões relativas à medida socioeducativa em tela deriva-se do fato de que estudos realizados sobre o sistema de atendimento ao adolescente em conflito

1 Endereço: Rua Barão de S. Francisco 120, apt. 801, Rio de Janeiro, RJ, Brasil 20560-030.E-mail: torraca@uerj.br

2 Artigo 118 do ECA - A liberdade assistida será adotada sempre que se afigurar a medida mais adequada para o fim de acompanhar, auxiliar e orientar o adolescente.

1) A autoridade designará pessoa capacitada para acompanhar o caso a qual poderá ser recomendada por entidade ou programa de atendimento.

2) A liberdade assistida será fixada pelo prazo mínimo de seis meses, podendo a qualquer tempo ser prorrogada, revogada ou substituída por outra medida, ouvido o orientador, o Ministério Público e o Defensor. com a lei no Brasil (Albergaria, 1991; Frota \& Silva, 2001) apontam que, em decorrência da compreensão dos prejuízos que a internação pode acarretar ao desenvolvimento dos jovens, a liberdade assistida tem sido freqüentemente adotada pelos juizados da infância e da juventude do país.

\section{Breve Histórico}

Alguns autores esclarecem que o atendimento em liberdade daqueles acusados de terem cometido infração penal acha-se relacionado ao conceito da probation, instituto angloamericano, como explica Albergaria (1991). Esse instituto encontrou respaldo nas atividades desenvolvidas por grupos de reformadores cristãos que, no século XIX, se ofereciam para supervisionar infratores.

Evidentemente a iniciativa privada inicial foi uma comodidade e um benefício para tribunais sobrecarregados de pequenos delinqüentes cujos crimes deviam, no mais das vezes, estar associados à pobreza material e ao consolo alcoólico para o qual as massas submersas se voltavam a fim de fugir de sua cansativa rotina em um século de grande e crescente desigualdade econômica. (Playfair \& Sington, 1965/1969, p. 177)

Enfatizam esses autores que o tratamento, na época, consistia na reprovação moral aliada a penitências ou ainda a castigos físicos, a partir da visão dominante de que tais infratores seriam portadores de defeitos morais.

Platt (1997), ao estudar o movimento reformista nos Estados Unidos, destaca que os membros desses grupos colaboraram para construir a idéia dos tribunais para menores 
de idade. Vistos, na época, como altruístas e humanitários, os reformadores dedicavam-se a salvar aqueles menos afortunados preocupando-se, sobretudo, com a identificação e o controle do mau comportamento de crianças e adolescentes. Optando também por um viés crítico, Donzelot (1986) analisa que, na França, no final do século XIX, “(...) a colaboração entre a justiça e as obras filantrópicas produziu um sistema que pré-figurava a atual liberdade vigiada e a assistência educativa em meio aberto" (Donzelot, 1986, p. 81).

Relatam Playfair e Sington (1965/1969) que, em meados do século XX, o sistema de probation havia alcançado poucos progressos na Inglaterra, motivo pelo qual era visto como um recurso falível para a reabilitação de delinqüentes. Naquele sistema valorizava-se, primordialmente, o comparecimento sistemático do assistido à instituição onde deveria comprovar - a seu orientador - que estava trabalhando e/ou estudando. Cada orientador, denominado probation officer, era responsável por um elevado número de casos, o que dificultava um atendimento adequado às necessidades individuais.

No Brasil, o primeiro Código de Menores, de 1927, trata o atendimento em meio aberto como liberdade vigiada. Já o Novo Código de Menores, em vigor de 1979 a 1990, dispõe, no artigo $38^{3}$, sobre a medida de liberdade assistida que poderia ser empregada tanto para os acusados da prática de delitos como para casos de desvio de conduta, como assinala Porto (1999).

De acordo com a política tutelar do Código de 1979, eram três as medidas mais utilizadas, especificamente, com os então denominados menores infratores: internação, liberdade assistida e advertência. No entanto, como explica Amaral (1990), o Código não previa medidas de apoio à família. No que diz respeito à liberdade assistida, esta era entendida como modalidade de tratamento inserida no domínio da Criminologia Clínica. Como exemplo pode-se citar explicação de Albergaria (1991) ao se referir à aplicação dessa medida aos jovens considerados em situação irregular, conforme entendimento da doutrina que regia aquele Código:

Sob o enfoque das ciências humanas a liberdade assistida se define como modalidade de tratamento em meio livre, com prévio estudo médico-psicopedagógico e social da personalidade do menor, elaboração do programa de reeducação e sua execução por pessoal especializado. O tratamento seria o traço característico da liberdade assistida (Albergaria, 1991, p. 13).

Desponta, naquele âmbito, o trabalho desenvolvido por equipes multidisciplinares que deveriam identificar as patologias sociais, psicológicas, pedagógicas e psiquiátricas apresentadas pelos jovens, tidas como causa absoluta da delinqüência. Assim, ao tratamento antecedia um rigoroso diagnóstico, elaborado, quase sempre, pela equipe técnica. Esta deveria fornecer esclarecimentos sobre características

3 Artigo 38. Aplicar-se-á o regime de liberdade assistida nas hipóteses previstas nos incisos Ve VI do artigo 2 desta Lei, para o fim de vigiar, auxiliar, tratar e orientar o menor.

Parágrafo único - A autoridade judiciária fixará as regras de conduta do menor e designará pessoa capacitada ou serviço especializado para acompanhar o caso. de personalidade dos atendidos esmiuçando as condições de desenvolvimento destes, informações colhidas, geralmente, a partir de longas anamneses realizadas com as mães ou responsáveis. Com os jovens, entrevistas, testes de inteligência e de personalidade completavam o exaustivo processo diagnóstico.

Estudos e exames empreendidos sobre a personalidade de crianças e adolescentes serviam não só para compor diagnósticos psicológicos, como também para fornecer prognósticos e sugestões quanto ao atendimento a ser desenvolvido. Nos relatórios confeccionados pelos profissionais constavam, basicamente, os seguintes itens: identificação do jovem, apresentação do caso, hipóteses diagnósticas - com fortes ênfases em carências biopsicossociais - e prognóstico. Nesses procedimentos, as organizações familiares dos jovens atendidos eram constantemente classificadas como desestruturadas devido, geralmente, à precariedade socioeconômica em que viviam ou ao fato de haver grande número de mães separadas que passavam parte do dia fora de casa, o que era interpretado como abandono dos filhos ou ausência de vínculos afetivos com estes. Dessa maneira, a autoridade familiar era desqualificada, enquanto a preocupação do atendimento centrava-se na autonomia a ser atingida pelo jovem. Nesse sentido, Batista (1998), ao analisar pareceres produzidos por equipes de liberdade assistida que atuavam, naquele período, junto ao Juízo de Menores do Rio de Janeiro, concluiu que: "o olhar moral e periculosista que esses técnicos lançaram às noções de família, trabalho e moradia é digno de nota” (Batista,1998, p. 107).

A correlação entre presença de patologias e cometimento de ato infracional era defendida por muitos que apostavam na assistência psicológica, de base clínica, a esses jovens. Concebia-se o ato anti-social praticado por crianças ou adolescentes como um sintoma. Em conseqüência, o conceito de melhora encontrava-se relacionado à supressão desse. De maneira semelhante, a vivência junto a estruturas sociais desfavoráveis era interpretada como causa do aparecimento de distúrbios psíquicos, os quais deveriam ser imediatamente tratados. Como percebe Amaral (1990), na doutrina da situação irregular as medidas aplicadas eram direcionadas ao tratamento de patologias, porém, as diversas situações sociais irregulares não eram objeto de preocupação, tampouco existiam propostas imediatas para alterá-las.

Naquela época, os programas de liberdade assistida priorizavam o atendimento dos jovens por profissionais de diferentes áreas de conhecimento, como serviço social, psicologia, pedagogia e psiquiatria. Por vezes, os assistidos deveriam ser atendidos por profissionais das quatro áreas no mesmo dia, em distintos horários, sendo nítido o quanto não distinguiam a diferença de abordagens. Era comum se observar o adolescente percorrendo várias salas de atendimento, tonto, com um cartão de consultas na mão, perguntando: " $E$ agora, para onde vou?"

Visto pelo âmbito clínico, o tratamento deveria ser individual, com todas as atividades realizadas dessa maneira. Ao longo do atendimento terapêutico do jovem algumas dificuldades, interpretadas como resistências, eram constantemente salientadas nos relatórios como por exemplo o silêncio mantido nas entrevistas, caracterizado como defesa. Outros jovens, no entanto, preferiam centrar seu discurso nos adequados 
planos que estavam traçando para o futuro, acreditando que dessa forma seriam logo liberados das consultas.

\section{Reorientação na Política de Atendimento}

Com a promulgação do Estatuto da Criança e do Adolescente em 1990, novos parâmetros para o atendimento de crianças e adolescentes se fazem necessários seguindo-se, agora, indicação da doutrina de proteção integral. Dessa forma, o modelo anteriormente adotado passa a ser visto como superado, sendo indicadas mudanças na política de atendimento.

Alguns autores ressaltam a distinção que deve ser feita, inicialmente, entre o conceito de liberdade vigiada e o de liberdade assistida, agora, na vigência da doutrina de proteção integral. Enquanto a liberdade vigiada era estabelecida basicamente como instrumento para controle de comportamento em conseqüência do ato infracional praticado, a liberdade assistida, nos parâmetros da doutrina de proteção integral, deve estar voltada para os saudáveis vínculos a serem mantidos ou estabelecidos entre o adolescente e seu grupo doméstico e comunitário. Acredita-se, como descreve Della Giustina (1998), que: "essa medida reconstrói no adolescente a sua atividade, os seus valores, a sua convivência familiar, social, escolar e profissional" (p. 50).

Seguindo essa lógica, observa-se em uma proposta atual de execução de liberdade assistida, a necessidade de se romper com práticas e procedimentos comumente utilizados nos antigos serviços de L A, desconstruindo-se referenciais vigentes por ocasião da doutrina da situação irregular, base do Código de 1979. Se a doutrina de proteção integral altera a compreensão sobre as políticas que devem ser priorizadas no atendimento à parcela infanto-juvenil de nossa sociedade, deve modificar também, em sua essência, a execução das medidas socioeducativas. Como já se afirmou (Brito, 2000) ao analisar avaliações empreendidas por equipes do sistema socioeducativo:

O compromisso, agora, é com os direitos desses jovens, direito de não continuar cometendo infrações, direito de ter uma vida digna, direito de ser incluído nas políticas públicas. Para tanto, temos de apontar não simplesmente suas patologias (patologias segregam, afastam,) mas as indicações para o completo desenvolvimento, seguindo-se os parâmetros indicados no Estatuto, ou seja, o que está sendo oferecido para promover seu direito à saúde, à educação, à convivência familiar e comunitária (Brito, 2000, p. 124).

Compreende-se, portanto, que a liberdade assistida, medida que muitos afirmam conhecer e aplicar há muitos anos, requer, no contexto da doutrina da proteção integral, novo entendimento e novas modalidades de execução para que siga os parâmetros dispostos no ECA. Como já apontou Xaud (1999), torna-se impensável a manutenção de velhas práticas quando temos novos ideais.

Destaca-se contudo que ainda se observa, por vezes, a continuidade do antigo modelo de liberdade assistida, conforme atesta matéria publicada em 2001, por jornal de São Paulo, ao chamar atenção para a ineficácia dos programas locais que, segundo interpretam, funcionam como um pas- saporte para o ingresso de jovens no sistema penal. A citada reportagem dá destaque, também, ao excessivo número de casos a serem atendidos pelos profissionais que atuam junto aos serviços de liberdade assistida. "Cada técnico é responsável, em média, por 80 adolescentes" (Athias \& Biancarelli, 2001, p. C1). Situação que colabora para que os relatórios estejam, quase sempre, centrados em anotações burocráticas de comparecimento do jovem ao setor, à semelhança da tarefa executada por alguns probation officers. Em conseqüência, cabe recordar advertência de Soares (2001) de que:

Aplicar apenas formalmente uma liberdade assistida ou um arremedo de prestação de serviços à comunidade ou determinar uma reparação de danos meramente simbólica, ou fazer uma advertência que entra por um ouvido e sai pelo outro, é tão hipócrita como internar só para mostrar serviço à sociedade (Soares, 2001, p. 91).

Da mesma forma, compreende-se que breves citações nos relatórios de encaminhamentos feitos pela equipe do programa como "o adolescente se alistou nas Forças Armadas" ou "tirou o título de eleitor", não traduzem a dimensão do atendimento efetuado por programa de liberdade assistida, assim como não esclarecem sobre a prática de trabalho desenvolvida. Providências para regularizar a documentação do adolescente podem propiciar, por exemplo, uma ótima oportunidade para se abordar, com este e com sua família, o significado desses ingressos institucionais e pertencimentos sociais. Quem não ouviu falar das ansiedades e receios, muitas vezes gerados por histórias fantasiosas, de meninos que se encontram às vésperas da apresentação para o alistamento militar? Qual o significado social e político do título de eleitor? Entende-se, portanto, que debater com grupos de jovens e de pais o significado do voto, do documento de identidade, do alistamento nas Forças Armadas, são, sem dúvida, procedimentos que colaboram com a cidadania dos atendidos, conceito que deve guiar um trabalho socioeducativo. Por essa razão, torna-se pertinente a seguir, o exame de diretrizes e propostas de atendimento que têm como norte a garantia de direitos de crianças e de adolescentes.

\section{Ampliando Ações e Responsabilidades}

Em acordo com o disposto no Estatuto da Criança e do Adolescente indica-se, atualmente, que os programas de liberdade assistida devem ser estruturados nos diferentes municípios, com atendimento a um número reduzido de adolescentes residentes na comunidade onde se encontra o programa. Para obterem êxito, devem receber apoio de projetos e instituições locais convidadas a colaborar com vistas à integração social dos jovens. Agora, a interação com postos de saúde, regiões administrativas, projetos de lazer, escolas e cursos profissionalizantes deve ser preocupação dos profissionais que atuam em programas de liberdade assistida. Como descreve Seda (1998) ao se referir aos programas desenvolvidos segundo o paradigma da proteção integral:

Ao mesmo tempo, esse programa organiza-se, metodiza-se, controla-se, avalia-se, estimulando, induzindo, orientando, ensinando, preparando a criança e o adolescente, e seus parentes e seus amigos, etc, para pensarem-se e sentirem-se sujeitos $e$ 
cidadãos. Programas de Proteção e Programas Sócio-Educativos são programas de cidadania (Seda, 1998, p. 48).

O Estatuto da Criança e do Adolescente prevê também, na execução da medida de liberdade assistida, a figura de um orientador, que pode ser um voluntário que se encarregará de assistir o jovem no cumprimento da medida. A missão desse voluntário, aliás, faz recordar a dos tutores sociais - membros de instituições filantrópicas que, no século XIX, se ofereciam para ocuparem-se dos jovens - descritos por Donzelot (1986, p. 96) como "colaboradores institucionais do juiz". Atualmente, o detalhamento das atribuições desse orientador, que irá atuar na denominada liberdade assistida comunitária, vem sendo estabelecido por cada programa, pois como questiona Napoli (2003): "a pergunta é embaraçosa: afinal, o que seria essa soturna tarefa de assistir à liberdade alheia?” (p. 28).

Seguindo indicação da legislação, um projeto socioeducativo a ser cumprido pelo jovem deve ser elaborado, prevendo-se atividades consideradas adequadas ao desenvolvimento deste. Desenvolvimento que para ser alcançado deve ter como garantia os direitos listados no ECA, ou seja, direito à saúde, à educação, à convivência familiar e comunitária, entre outros.

No decorrer do cumprimento da medida observa-se que não cabe à equipe limitar seu trabalho a anotações sobre o comparecimento ou não da família do adolescente ao programa. Deve-se, agora, investir no atendimento familiar, pois como alerta Youf (2000), esses são os principais responsáveis pela educação de crianças e adolescentes, motivo pelo qual o apoio à tarefa educativa dos pais deve ser prioridade. Com vistas a uma educação para a cidadania, o conteúdo educativo e responsabilizante da medida deve ser apresentado e discutido com o jovem e seus responsáveis. Com esse objetivo, pode-se também promover debates com os familiares, estimulando o acompanhamento e entendimento das várias dificuldades e ansiedades pelas quais passam os jovens nessa fase de desenvolvimento, encaminhamento que, com certeza, é distinto da atribuição de culpa à família pelo ato que o adolescente praticou.

Compreende-se, portanto, que a equipe não deve restringir sua atuação com o grupo familiar ao contexto do processo diagnóstico com o objetivo de proceder a um nexo causal entre as mazelas daquele núcleo familiar e $\mathrm{o}$ ato infracional praticado pelo adolescente. Contrariamente, hoje se percebe, como explica Salas (1998, p. 175), que o jovem acusado da prática de ato infracional traz à tona, na verdade, as patologias de toda uma sociedade. Da mesma forma, no contexto da doutrina de proteção integral, as famílias são pensadas como aliadas no processo de desenvolvimento de crianças e de adolescentes. Como ressalta Takashima (1994):

Abordar e mediar famílias, na tentativa de apoiá-las e fortalecêlas em seu dia-a-dia, através de políticas de atendimento, é o grande desafio, na medida em que se constituem por partes que se relacionam entre si, de forma que uma não pode prescindir da outra (Takashima, 1994, p. 80).

Trabalhar com uma rede de apoio à família torna-se, por conseguinte, fundamental. Para isso, é preciso localizar na comunidade iniciativas de organizações governamentais ou não-governamentais para que possam formar essa rede com atendimento integrado. Caminha-se ao rumo de uma maior interação do indivíduo com sua família e sua comunidade, ampliando-se serviços comunitários e estimulando-se parcerias, sem dúvida movimento articulado às políticas públicas. Não se pode conceber, no entanto, que famílias muitas vezes em precárias situações econômicas, com difíceis histórias de vida, enfrentando contextos sociais adversos, encontrem, sem qualquer ajuda, encaminhamentos ou soluções para as suas questões. Como esclarece Wyvekens (1998): “os pais fragilizados tanto no plano econômico como cultural carecem de assistência, de referências que lhes permitam saber o que eles podem exigir de seus filhos" (p. 172). Recorda-se que, em contexto socioeconômico distinto, diversas famílias procuram psicólogos ou psicanalistas visando a um processo de ajuda.

Deve-se colaborar ainda com formas de ação grupal de apoio procurando, por meio coletivo, organizar ações que forneçam respaldo às difíceis situações vivenciadas por aqueles com problemáticas similares. Destaca-se aqui exemplo citado por profissional com atuação junto a Programa de LA que expôs, no decorrer de um curso, sobre a dificuldade de alguns jovens conseguirem fotografias necessárias para os documentos que precisavam providenciar. Em articulação com os recursos existentes na comunidade, surgiu proposta de averiguar-se a possibilidade de um fotógrafo da localidade fornecer o serviço como colaboração voluntária. E quem sabe, a partir daí, propor que aquele menino que sempre disse gostar de tirar e/ou contemplar fotos, e que um dia pensou em aprender o ofício, pudesse começar a ajudar esse profissional.

Se por muito tempo o assistencialismo foi a tônica do atendimento familiar favorecendo atitudes de passividade pela pessoa atendida, agora o foco deve estar direcionado para o viés participativo, colaborando-se com a busca de formas de organização e desenvolvimento daquela comunidade. Nesse sentido, se o programa de liberdade assistida está localizado em uma determinada área geográfica e atua com jovens que ali residem, a proposta acima é facilitada, já que os responsáveis, geralmente, também habitam no local, vivenciando problemas comuns. Pode-se assim estimular, por meio de reuniões e debates, o início de uma forma diferenciada de organização e de ajuda mútua. Como já destacado por Groisman e Kusnetzoff (1984): “ocupar-se da adolescência é ocupar-se da intricada rede que faz do jovem um emergente significativo" (p. 6).

Como exemplo de ações comunitárias pode-se recordar iniciativas existentes em outros países, como creches organizadas por pais, na França (Combes, 1994), ou ainda as associações de avós ocasionais, que oferecem a possibilidade de cuidar de crianças em horários pré-estabelecidos, sem ônus financeiros para os pais. Iniciativas que, em algumas de nossas comunidades, poderiam ser viabilizadas, já que são comuns as queixas de pais quanto à inexistência de local adequado para deixar seus filhos, antes ou após o horário do colégio. Nessa última proposta, comumente reúne-se um pequeno número de idosos que oferecem essa ajuda à comunidade. Por meio dessa colaboração voluntária possibilita- se não só a interação entre idosos como são promovidos encontros intergeracionais. Para a realização da tarefa, as voluntárias disponibilizam a casa de uma delas ou a própria comunidade fornece um local de referência para a 
creche alternativa. Motivadas pela incumbência do cuidado infantil, as avós podem, por exemplo, contar histórias para as crianças, jogar com estas ou até oferecer os doces sonhos, comestíveis ou não, da vovó.

Com tais iniciativas colabora-se com respostas às dificuldades e necessidades das famílias, não só no que diz respeito ao jovem assistido, mas permitindo que outros membros do grupo familiar sejam beneficiados, ampliando a rede acolhida por meio de recursos da própria comunidade.

Entre a tentação de continuar-se a penalizar as famílias e o desenvolvimento de propostas que funcionem como suporte para que consigam melhor exprimir ou manter a autoridade parental, indica-se a opção pela segunda possibilidade. Como sugere Salas (1998), ao abordar o atendimento educativo de jovens em conflito com a lei, hoje o Estado deve romper com uma lógica de atendimento estritamente individual, buscando o trabalho com o ambiente familiar e procurando restaurar a autoridade dos pais.

\section{Conclusão}

Observa-se que apesar de ter-se mantido a denominação de liberdade assistida para uma das medidas socioeducativas previstas no Estatuto da Criança e do Adolescente, essa não deve ser executada da mesma maneira que à época do Novo Código de Menores. O Estatuto da Criança e do Adolescente, com fundamento na doutrina de proteção integral, traz uma nova orientação à Justiça da Infância e da Juventude, com mudanças na concepção do atendimento direcionado às crianças e aos adolescentes, alteração que não poderia deixar de repercutir na execução das medidas socieducativas. Impõe-se, assim, ampla revisão de conceitos e práticas, alterações que abrangem o trabalho das equipes técnicas.

Por ocasião da doutrina da situação irregular, o tratamento aplicado aos jovens que haviam praticado ato infracional visava à cura de suas patologias, sendo necessário amplo estudo diagnóstico que revelasse as características da personalidade do atendido, em acordo com pressupostos da chamada criminologia clínica. Suas famílias eram vistas como desestruturadas, portanto optava-se pelo discurso que priorizava o atendimento individual do assistido para que se conseguisse autonomia, desconsiderando a irregularidade das questões sociais que atingiam-no.

Agora, no contexto da doutrina de proteção integral, o atendimento visa primordialmente a assegurar os direitos dos jovens atendidos, direitos listados no ECA como fundamentais ao desenvolvimento de crianças e adolescentes para que possam alcançar, com propriedade, a maioridade jurídica. Para tal, os caminhos individuais, familiares e comunitários podem ser múltiplos, articulados, todavia, às políticas públicas, considerando que o desenvolvimento de crianças e adolescentes é um compromisso a ser assumido pela família, pelo Estado e pela sociedade.

Abrem-se as portas das salas de atendimento, direcionando o trabalho para procedimentos que visem à colaboração com a garantia de cidadania dos assistidos, o que requer constante interação com os recursos públicos e com aqueles que surgem de organizações comunitárias.
Despontam, portanto, novos horizontes para a atuação de equipes profissionais que lidam no contexto socioeducativo, com amplas possibilidades de execução da medida de liberdade assistida.

\section{Referências}

Albergaria, J. (1991). Liberdade assistida. Revista da Escola do Serviço Penitenciário do Rio Grande do Sul, 7(4/5), 9-20.

Amaral, A. F. (1990). O E. C. A. e o Código de Menores. Em E. Arantes \& M. E. Motta (Orgs.), A criança e seus direitos (pp. 9-16). Rio de Janeiro: PUC/RJ - FUNABEM.

Athias, G. \& Biancarelli, A. (2001). A cada dia um ex-interno vai para a prisão. Folha de São Paulo. Caderno Cotidiano, 19 agosto, p. C1-C3.

Batista, V. M. (1998). Dificeis ganhos fáceis - drogas e juventude pobre no Rio de Janeiro. Rio de Janeiro: Instituto Carioca de Criminologia Freitas Bastos.

Brito, L. M. (2000). Avaliação dos adolescentes pelas equipes que atuam no sistema sócioeducativo. Em L. M. Brito (Org.), Jovens em conflito com a lei (pp. 115-126). Rio de Jáneiro: Eduerj.

Combes, J. (1994). Les crèches parentales. Pôles d'ancrage de réseaux de solidarité. Em S. Terrier (Org.), L'enfant et son integration dans la cité (pp. 55-64). Paris: Syros.

Della Giustina, J. (1998). Medidas socioeducativas em meio aberto: prestação de serviços à comunidade e liberdade assistida. Em Ministério da Justiça (Org.), Políticas públicas e estratégias de atendimento socioeducativo ao adolescente em conflito com a lei (pp. 47-52). Brasília: Ministério da Justiça.

Donzelot, J. (1986). A polícia das famílias. (M. T. Albuquerque, Trad.). Rio de Janeiro: Graal.

Estatuto da Criança e do Adolescente (1990). Diário Oficial da União. Lei Federal n 8.069, de 13 de julho de 1990. Brasília, DF.

Frota e Silva, P. S. (2001). Alternativas à aplicação de medidas socioeducativas. Em Associação Beneficente São Martinho (Org.), No mundo da rua: alternativas à aplicação de medidas socioeducativas (pp. 94-104). Rio de Janeiro: Associação Beneficente São Martinho.

Groisman, M. \& Kusnetzoff, J. C. (1984). Adolescência e saúde mental. Porto Alegre: Artes Médicas.

Napoli, C. (2003). Liberdade assistida: a construção de um novo espaço. Em F. O. Barros (Org.), Tô fora: o adolescente fora da lei (pp. 25-40). Belo Horizonte: Del Rey.

Platt, A. M. (1997). Los "salvadores del niño" o la invención de la delincuencia. Madrid: Siglo Veintiuno Editores.

Playfair, G. \& Sington, D. (1969). Prisão não cura, corrompe. (A. Arruda, Trad.) São Paulo: Ibrasa. (Trabalho original publicado em 1965)

Porto, P. C. (1999). As medidas socioeducativas. Em Cendhec (Org.), Sistema de Garantias de Direito (pp. 239-252). Recife: Câmara de Ação Social.

Salas, D. (1998). Refonder 1' Etat educateur. Esprit, 241 (3/4), 174-188.

Seda, E. (1998). A criança e sua Convenção no Brasil. São Paulo: Conselho Regional de Psicologia/SP.

Soares, J. J. B. (2001). Alternativas à aplicação de medidas socioeducativas. Em Associação Beneficente São Martinho (Org.), No mundo da rua: alternativas à aplicação de medidas socioeducativas (pp. 89-94). Rio de Janeiro: Associação Beneficente São Martinho. 
Takashima, G. M. (1994). O desafio da política de atendimento à família: dar vida às leis - uma questão de postura. Em S. M. Kaloustian (Org.), Família brasileira, a base de tudo (pp. 7792). São Paulo: Cortez, Brasília: Unicef.

Wyvekens, A. (1998). Délinquance dês mineurs: justice de proximité vc justice tutélaire. Esprit, 241(3/4), 158-173.

Xaud, G. M. (1999). Os desafios da intervenção psicológica na promoção de uma nova cultura de atendimento do adolescente em conflito com a lei. Em L. M. Brito (Org.), Temas de Psicologia Jurídica (pp. 87-102). Rio de Janeiro: RelumeDumará.
Youf, D. (2000). Repenser le droit penal des mineurs. Esprit, 255(10), 87-112.

Recebido em 03.05.2006

Primeira decisão editorial em 27.07.2006

Versão final em 29.08.2006

Aceito em 26.01.2007

\section{INTERESSADO EM AGILIZAR A PUBLICAÇÃO DE SEU ARTIGO?}

\section{Informações e dicas para os autores sobre aspectos operacionais}

\section{O manuscrito é reencaminhado pelo autor em versão reformulada}

Quando a versão reformulada é aceita e são poucos os reparos, as correções necessárias são feitas na secretaria da revista. Com a versão atualizada em formato eletrônico, o processamento pode ser imediatamente iniciado. Na falta destas informações, não é possível o processamento de correções nem a preparação do manuscrito para editoração. Em suma, atraso para entrar no prelo.

\section{Informações e dicas para os autores com artigos no prelo}

\section{O manuscrito é encaminhado para editoração}

No caso de o manuscrito ser aceito para publicação, é esperada a participação do autor no processo de preparação do artigo na fase de editoração. A primeira prova do artigo, editada a partir da versão em disquete ou CD-R, é enviada para exame ao(s) autor(es). O prazo para devolução é de 48 horas. A obediência ao prazo permite a manutenção da composição prevista para o volume/número da revista. $\mathrm{O}$ atraso no envio da prova examinada pode implicar em mudanças na composição de um número no prelo. E pode resultar em atraso na edição final. 